\section{NCCN Guidelines and Their Impact on Coverage Policy}

The NCCN has had, from its inception, the guiding objective of "positively influencing and improving decisions that influence and impact the access to, availability of, utilization of, and delivery of appropriate cancer care on behalf of patients. "This has not been some idle axiom. NCCN has sought to actively develop and communicate the Guidelines information in formats most useful to end-user groups. It is critical that provider scientific/clinical organizations do so to assert what are the most appropriate and effective interventions for patients with cancer.

\section{Coverage Policy}

The most striking application of the NCCN scientific, evaluative, and evidence-based information is the story of the NCCN Drugs $\mathcal{E}$ Biologics Compendium. In late 2004, NCCN decided to transpose and translate recommendations about the use of drugs and biologics in the NCCN Guidelines into a compendium format-listings of appropriate uses of drugs and biologics. Indeed, in the late 1980s and early 1990s, laws were passed in 32 states that mandated the use of 3 compendia (AMA Drug Evaluations, USP-DI, AHFS Formulary) by private payers to decide on coverage for the use of drugs.

These laws were precipitated by an insurance practice of denying uses of drugs not explicitly approved by the FDA (on the FDA labels) for them. In oncology, this was a major issue because, at the time, upwards of $50 \%$ of the use of drugs was beyond the scope of the FDA label. Indeed, for patients with the serious and lifethreatening diagnosis of cancer, denial of a drug with evidence supporting its use was a major concern and serious threat to that patient's life expectancy. Conversely, if a compendium indicated a use was appropriate or was listed, the private payer had to cover that use of that drug. In 1993, the Congressional Omnibus Budget Reconciliation Act included a provision that mandated that the Medicare program do the same. In 1994, this legislative provision was incorporated into regulation and followed by formal guidance to intermediaries and carriers that required the compendia to be the basis for coverage determinations.

In January of 2008, United HealthCare (UHC), the largest private payer in the United States, announced that UHC would be the first private payer to base coverage determinations about the use of drugs and biologics in cancer care on the NCCN Compendium. This announcement has been followed by communications from most other large private payers that they would also use the NCCN Compendium as the basis for coverage policy and determinations. On June 5, 2008, CMS announced that the NCCN Compendium would be become a mandated resource to be used by Medicare contractors for the establishment of coverage policy.

The importance of these announcements is that within 10 years, NCCN has been able to flip the decision-making system so that an organization of major cancer centers and their physician thought leaders, after review of scientific evidence, put forth recommendations about what constitutes appropriate care for patients and these recommendations are being followed and adhered to by public and private payers.

In summary, NCCN has successfully adapted the content of the NCCN Guidelines into formats, like the NCCN Compendium, that inform and facilitate decisionmaking about appropriate interventions in oncology. These different decision formats or tools serve to assure that innovative technologies are available for appropriate use in patients based on positive coverage determinations by public and private payors.

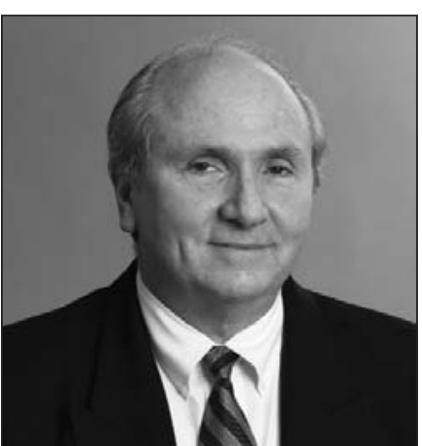

William T. McGivney, PhD

William T. McGivney, PhD, is Chief Executive Officer of the NCCN, responsible for the development of strategies and programs to improve the quality of care available to cancer patients. Such programs include the NCCN Clinical Practice Guidelines in Oncology, NCCN Oncology Outcomes Database, NCCN Oncology Research Program, and NCCN Drugs \& Biologics Compendium. Strategically, $\mathrm{Dr}$. McGivney is responsible for the growth of NCCN's influence in the oncology community and for assuring the development of partnerships with managed care companies and employers, the development of NCCN's health information capabilities, and the expansion of centralized research programs.

Before joining NCCN, Dr. McGivney was Director of the Division of Health Care Technology at the American Medical Association and then Vice President for Clinical and Coverage Policy at Aetna Health Plans. While at Aetna, he helped establish the first formal independent outside review process.

Dr. McGivney, a recognized expert in coverage policy and in drug and device regulatory policy, was awarded the FDA Commissioner's Medal of Appreciation in 1989. He has served on numerous national boards and committees including as President of the Board of the Patient Advocate Foundation and National Patient Advocate Foundation and as a member of the UNOS Board of Directors and the Medicare Coverage Advisory Committee.

The ideas and viewpoints expressed in this editorial are those of the author and do not necessarily represent any policy, position, or program of the NCCN. 